\title{
Interesse público ou entretenimento: que tipo de informação o leitor procura na internet?
}

\section{Camilla Quesada Tavares e Michele Goulart Massuchin}

\section{Resumo}

0 artigo apresenta resultados de uma pesquisa sobre as preferências dos leitores de dois portais informativos brasileiros - G1 e UOL - feita a partir das notícias mais acessadas. 0 objetivo é verificar se há tendência de segmentação entre os portais, propondo uma análise comparativa dos anos de 2012, 2013 e 2014. Ao todo, foram coletadas 2.637 notícias pertencentes às seções "mais lidas do dia". A metodologia utilizada é quantitativa de análise de conteúdo e os resultados indicam que há segmentação entre os portais- enquanto o G1 é mais buscado para consumo de notícias de interesse público, o UOL é acessado para entretenimento. Por outro lado, apesar de a segmentação se manter nos três anos pesquisados, 0 interesse por notícias que envolvem questões políticas cresceu entre 2012 e 2014.

\section{Palavras-Chave}

Portais de notícias. Interesse público. Entretenimento.

\section{Camilla Quesada Tavares ।}

camilla.tavares8@gmail.com

Doutoranda em Comunicação pela Universidade Federal Fluminense - UFF, Brasil. Professora do Departamento de Jornalismo da Universidade Estadual de Ponta Grossa - UEPG, Brasil. Pesquisadora do Laboratório de Mídia e Democracia (LAMIDE/UFF) e do Grupo de Estudos e Pesquisas em Mídias Digitais (GEMIDI/UEPG).

\section{Michele Goulart Massuchin ।}

mimassuchin@gmail.com

Doutora em Ciência Política pela Universidade Federal de São Carlos - UFSCar, Brasil. Professora adjunta do Curso de Comunicação Social - Jornalismo da Universidade Federal do Maranhão - UFMA, Brasil. Coordenadora do Grupo de Pesquisa em Comunicação, Política e Sociedade (UFMA).

\section{Introdução}

Este $\operatorname{artig} 0^{1}$ discute 0 interesse dos leitores dos portais informativos a partir da análise das notícias que são mais acessadas em dois grandes portais de notícias brasileiros - G1 e UOL. 0 estudo analisa se a tendência de segmentação do público leitor entre os portais - resultado encontrado em pesquisas anteriores, de que alguns atendem ao entretenimento e outros a temas de interesse público $^{3}$ - tende a se conservar, por meio de uma análise comparativa que compreende o período entre duas campanhas eleitorais brasileiras: 2012, 2013 e 2014; e de que maneira as notícias sobre entretenimento e interesse público disputam espaço na atenção do leitor na rede.

0 objetivo geral da pesquisa busca responder a seguinte pergunta: 0 interesse do leitor muda conforme o período - eleitoral e não-eleitoral - e o portal acessado? Para responder esta pergunta, analisam-se 2.637 notícias de ambos os portais, as quais foram categorizadas tendo como base 
um livro de codificaçã $0^{4}$. A hipótese principal sustentada é a de que existe uma segmentação do público leitor de acordo com o portal e 0 interesse por determinados tipos de notícia tende a mudar de acordo com o período (ano eleitoral e não-eleitoral).

É importante ressaltar que para discutir a segmentação do interesse do público, partese da dicotomia entre hardnews e softnews, levando em consideração o tema das notícias. Assim, compreende-se que notícias hardnews são de interesse público e coletivo e que aqui englobam os temas políticos, sociais e eleitorais, ao contrário das softnews, que tendem a abordar entretenimento e celebridades (TUCHMAN, 1983; ZALLER, 2003). Trabalha-se com essa dicotomia para discutir a tabloidização, na perspectiva de Chagas (2016), o que seria aplicável também à produção jornalística online, que tem tentado se aproximar mais de um modelo de entretenimento.

0 texto está dividido em quatro partes. 0 tópico a seguir é dedicado à discussão teórica que embasa o estudo, a qual está pautada principalmente pelo papel que os meios de comunicação de massa, de modo geral, e o jornalismo, de modo particular, exercem em período eleitoral e como a internet e a disputa por temas mais populares muda as lógicas de produção e de consumo. Posteriormente, faz-se a apresentação dos procedimentos metodológicos e das variáveis utilizadas na pesquisa. A terceira seção é dedicada à apresentação e análise dos dados empíricos e, por fim, apresentam-se as conclusões.

\section{Jornalismo on-line, tipos de conteúdo e a audiência ativa}

0 jornalismo praticado pelos grandes veículos de comunicação sofreu interferências das potencialidades da internet a partir do momento em que estes migraram para a rede. Se antes era necessário um gatekeeper que selecionasse e ordenasse as notícias "mais importantes" para o público ter acesso (SHOEMAKER; VOS, 2011), baseado em diversos critérios de noticiabilidade (WOLF, 2010), no ambiente online há uma elasticidade dos filtros noticiosos

Uma versão preliminar deste artigo foi apresentada no Congreso Latinoamericano de Ciencia Política, organizado pela Asociación Latinoamericana de Ciencia Política (ALACIP), em julho de 2015.

A primeira parte desta pesquisa, realizada em 2012, teve apoio financeiro do Instituto de Pesquisa UOL e foi orientada pelo prof. Dr. Emerson Urizzi Cervi. As autoras também agradecem os ex-alunos de Jornalismo da UEPG, Edgar Ribas e Aline Czezacki Kravutschke, que auxiliaram no processo de coleta de dados.

3 Ver resultados anteriores em: Cervi e Massuchin (2013). Diferente do artigo já publicado anteriormente, este traz uma comparação com um período não eleitoral (2013) e eleitoral nacional (2014), podendo observar a permanência e as mudanças de tendências a partir de contextos diferentes, 0 que a pesquisa anterior não possibilitava. 
aplicados pelos jornalistas (BARSOTTI, 2014). Isso se dá basicamente por um fator: 0 espaço quase que ilimitado possibilitado pela web. Para fins comparativos, Barsotti (2014) observa que 0 jornal impresso d'0 Globo, por exemplo, comporta 15 chamadas de capa, enquanto que na sua versão online é possível agregar 55 chamadas na home. Isso significa que, de acordo com a pesquisa da autora, a seleção dos acontecimentos - ainda que seja pautada pelos critérios de noticiabilidade - leva em conta um fator importante: 0 espaço disponível. Neste cenário, Barsotti (2014) constata que cerca de 80\% das pautas ofertadas às editoras online d'O Globo e do Extra são publicadas.

Os dois portais analisados neste trabalho, o G1 e UOL, embora tenham sido criados exclusivamente para a internet, possuem raízes nos grupos da mídia tradicional. 0 G1 se auto intitula como "o portal de notícias da Globo", e o UOL é ligado ao Grupo Folha. A grande diferença entre os dois veículos está no próprio conteúdo - enquanto que o UOL é nacional e mais abrangente, trazendo todo tipo de conteúdo em sua página, 0 G1 é segmentado por regiã $0^{5}$.

0 tipo de conteúdo que o público acessa na rede, no entanto, depende muito mais de seu interesse do que da abrangência do portal ou das prioridades elencadas pelos jornalistas. Massuchin e Tavares (2016) identificaram que as notícias de interesse público tendem a ocupar os locais de maior visibilidade em portais de notícias como Folha e G1. No entanto, isso não impede que o público busque por aquilo que lhe interessa, descartando a orientação temática imposta pelo layout dos sites. Um veículo pode dar mais espaço para notícias hard, mas o público acaba buscando mais por assuntos mais leves.

Analisando o contexto americano, Lima (2009) toma como objeto os sites da CNN, ABC News e CBS News para identificar 0 índice de composição dos conteúdos - mais voltados ao tabloide ou aos elementos tradicionais. Os resultados indicaram que há uma significativa tabloidização no conteúdo dos três websites. A autora sugere, ainda, que a competição com blogs de celebridade e 0 infotenimento está pressionando a mídia tradicional a adotar 0 estilo tabloide no ambiente online para recuperar a audiência. 0 entretenimento, pelo menos a partir desses três sites estudados, está ficando cada vez mais proeminente (LIMA, 2009).

Em pesquisa parecida com a proposta deste artigo, Lee (2012) identifica, a partir do estudo dos sites do New York Times e do The Washington Post, que notícias de entretenimento, como esportes, artes, cultura são mais "clicáveis" e, como consequência, supostamente mais lidas. No entanto, a autora encontrou uma forte correlação entre a agenda da mídia tradicional e as notícias mais lidas pelo público. 
Há ainda casos em que os conteúdos que figuram entre as mais lidas não ganham chamada de capa, mas a partir do momento em que entram no ranking são consideradas para integrar a home do site (BARSOTTI, 2014). Este é um exemplo de como a audiência interfere no processo de edição do jornalismo online. De forma complementar, Barsotti (2014), ao entrevistar editoras online d'0 Globo e Extra, descobriu que o ranking das mais lidas influencia, ainda, eventual "suítes" sobre 0 tema.

Com a pouca limitação de espaço, aumento na quantidade de conteúdo disponível e a possibilidade de buscar aquilo que mais lhe atende em termos de informação (NÓRA, 2011), o público se torna menos dependente de uma única fonte informativa. Se por um lado temos a mídia tradicional tentando se adaptar ao online - representada na figura de seus portais de notícias -, oferecendo informações que acredita serem as mais importantes para o conhecimento social, por outro se tem a necessidade de disponibilizar, neste mesmo espaço, notícias que não se norteiam pelo interesse público. Há aqui, segundo Chagas (2016), uma tendência de "tabloidização do jornalismo". 0 autor explica que a tabloidização é um processo que contamina a mídia "séria" por uma perspectiva e um estilo próprios do jornalismo popular.

Baseado nas classificações de Spark (2000), Chagas (2016) esquematiza o lugar da imprensa séria e da popular. Segundo o autor, a imprensa séria - formada pelos quality papers - buscaria pela concentração de temas políticos, econômicos e sociais, a partir da vida pública. No outro extremo, onde estão os tabloides de supermercado, haveria notícias concentradas na vida privada e baseadas em escândalos, esportes e entretenimento (SPARK, 2000 apud CHAGAS, 2016). Partindo da prerrogativa de que esta imprensa popular é massiva e possui maior audiência, a mídia tradicional sofreria, portanto, influência de uma dinâmica competitiva por popularidade (ESSER, 1999), na tentativa de se reaproximar dessa audiência (LIMA, 2009; CHAGAS, 2016). Tendo isso em vista, a demanda do público consumidor explicaria as mudanças no processo de produção dessa notícia (ZALLER, 2003), principalmente no ambiente online.

Isso reforça a tese de que a mídia vai adaptando a produção para aquilo que o público tem interesse - se preferem ler mais notícias hard ou soft (TUCHMAN, 1983), por exemplo. A discussão sobre hardnews e softnews é importante para esta pesquisa, uma vez que se busca identificar os temas que chamam mais a atenção dos leitores. Para isso, faz-se uma divisão temática entre os dois grupos. Tuchman (1983) identifica, a partir da entrevista com editores e jornalistas que atuam nas redações, dois tipos principais de notícias: as notícias duras - hardnews - e notícias brandas/leves - softnews ${ }^{6} .0$ primeiro 
grupo é caracterizado por eventos potencialmente disponíveis para análise ou interpretação, e que são baseados em apresentações de fatos ou eventos considerados de interesse jornalístico. São os assuntos relevantes socialmente para os cidadãos (TUCHMAN, 1983). Um exemplo disso seria a citação do presidente na República em delação premiada, denunciando sua participação em algum esquema de corrupção; ou ainda o aumento do preço do combustível que tem desdobramentos que atingem boa parte da população.

Em oposição às notícias duras, têm-se as brandas, ou leves. A principal característica deste tipo de conteúdo é que ele é de interesse do público (TUCHMAN, 1983), não tendo, necessariamente, relevância social. Elas são interessantes porque tratam da vida dos seres humanos ou questões que chama a atenção pela novidade ou, até mesmo, pelo bizarro. As matérias sobre celebridades e esportes, de modo geral, podem ser enquadradas nesta categoria; notícias que trazem histórias bizarras, como é o caso das publicadas na editoria "Planeta Bizarro", do G1, também integram o que adotamos como notícias softs.

0 tipo de notícia "leve" caracterizada por Tuchman (1983) tende a destacar-se na internet, também no que concerne 0 interesse dos leitores.
Vidal (2009) constata uma predominância do interesse do leitor por notícias que despertam 0 interesse do público em detrimento de notícias que tenham interesse público ${ }^{7}$.

Essa discussão leva à utilização de outro termo: 0 infotainment ${ }^{8}$. A definição, segundo Baym (2008), burla as tradicionais distinções entre conteúdos da programação televisiva até então orientados ou para a informação ou para o entretenimento. Para 0 autor, pode haver um tema hard no formato mais leve, como também pode haver notícias que evidenciam dramas e são personalizadas, ou seja, que são soft tanto no tema quanto no formato. Aguiar e Barsotti (2016) reforçam a posição de Baym (2008) e propõem que na forma entram as inovações na narrativa e no uso de termos menos formais, enquanto que no conteúdo se destaca a escolha de temas. Desde a criação no contexto britânico, outros estudos foram produzidos discutindo desde a sua definição (GOMES, 2009) até a aplicação para alguns casos específicos (MUNDIN, 2010; BERROCAL; CAMPOS; REDONDO, 2012).

Embora este estudo não se dedique a observar a forma como os conteúdos são apresentados, é importante pontuar que reconhecemos 0 entrelaçamento entre informação e entretenimento e que muitas notícias com temáticas hard

Uma linha complementar de estudos sobre entretenimento defende que as noticias leves podem ser, ainda, um caminho para as notícias hard. Prior (2003) argumenta que as notícias "leves" seriam uma maneira de chamar a atenção de pessoas que não se interessam por notícias "duras", como política, por exemplo, e levá-las a consumir esse tipo de conteúdo mais relevante por meio de notícias de entretenimento. 
podem ser trabalhadas a partir de elementos próprios do entretenimento. No entanto, para esta pesquisa, cujo objetivo é olhar apenas para as temáticas dos conteúdos, entende-se que notícias de entretenimento são de interesse do público e oferecem pouco subsídio para sustentar a discussão pública. Aqui, entende-se que 0 os meios de comunicação ajudam a compor 0 ambiente informacional dos indivíduos (CERVI, 2011), publicizando assuntos de interesse público que antes ficavam restritos à esfera privada (BLANCO, 2000). Assim, a discussão sobre 0 papel dos meios de comunicação - em especial, do jornalismo - principalmente em períodos eleitorais, ganha expressividade, já que eles tendem a agendar o público (McCOMBS, 2009) e a qualidade do debate estabelecido na esfera pública depende do tipo de informação consumida pelos indivíduos (HABERMAS, 2006).

Portanto, a partir desse raciocínio sobre a diferença entre os tipos de notícia associado à ideia de tabloidização devido ao interesse do púbico e a necessidade de adaptação dos veículos, pode-se sugerir que o ranking das notícias mais lidas do site é usado também como forma de avaliar e modificar a própria produção, no sentido de direcionar os produtores para aquilo que o público está acessando mais em cada portal (SHOEMAKER et al., 2010). Desse modo, trata-se de um processo complexo que permeia interesse do receptor e questões econômicas das empresas jornalísticas: os consumidores escolhem o que querem ler, os veículos se pautam nesse ranking para tentar se aproximar do interesse dos leitores

e, na sequência, produzem o que os leitores mais se interessarão e, assim, terão aumento de acesso às noticias. À luz dessa discussão é que analisamos os dados sobre os portais. Antes de passar a eles, apresentamos o desenho metodológico e as variáveis utilizadas.

\section{Metodologia de pesquisa e apresentação das variáveis}

Esta pesquisa analisa as notícias mais lidas do dia em dois portais diferentes: G1 e UOL. 0 corpus é composto por 2.637 entradas no banco de dados. Devido ao grande número de casos, optou-se pela metodologia quantitativa de análise de conteúdo, a partir da perspectiva da sistematização e codificação apresentada por Krippendorff (1990) e Bauer (2012). Optou-se, ainda, por uma abordagem quantitativa, sendo que Cervi (2009) explica que, aplicada às ciências sociais, representa os fenômenos a partir de um conjunto de técnicas que possibilitam medir e contar padrões.

As notícias extraídas dos portais fazem parte da seção "mais lidas do dia", que trata de uma seleção feita pelos próprios veículos, considerando a quantidade de acesso às matérias publicadas. Portanto é um ranking apresentado e disponibilizado pelos portais e não definido pelos pesquisadores. A seleção contava sempre com cinco textos ranqueados. A coleta foi feita diariamente e manualmente - sempre após às 
22 horas - durante 0 período de julho a outubro de 2012, 2013 e 2014 por um grupo de quatro codificadores. Os codificadores foram treinados a partir do livro de codificação, construído previamente. 0 período definido para a pesquisa compreende os 90 dias de campanha eleitoral em 2012 e 2014, sendo reproduzido também em 2013 para permitir comparações dos dados em período eleitoral e não eleitoral.

Dado 0 contexto da tabloidização que caracteriza, em especial, um dos portais, parte-se do pressuposto que os períodos prévios às eleições - como 2012 e 2014 seriam os períodos em que todos os veículos tenderiam a ter menos entretenimento. Ou seja, escolhem-se períodos em que não haveria uma superestimação deste tipo de conteúdo. Além disso, por ser considerado o período em que 0 tema político se aproxima mais dos cidadãos comuns, parte-se da hipótese de que aqui teríamos o "máximo" de buscas por notícias sobre política também.
As notícias foram categorizadas a partir de um livro de códigos ${ }^{9}$ previamente elaborado com uma série de características a serem observadas. Neste artigo, trabalha-se com a variável tema ${ }^{10} \mathrm{e}$ dela derivaram-se duas outras: "tipo de temática" divididas entre hardnews e softnews, a partir do conceito de Tuchman (1983) e Zaller (2003); e ainda o que chamamos de "mensagem geral", separada entre temas políticos, sociais e de entretenimento. Essa última subdivisão permite identificar a centralidade dos portais na disseminação de informação, especialmente sobre política, durante os períodos eleitorais de 2012 e 2014. Aqui são agrupados os dois subtemas políticos como "temas políticos", enquanto os demais temas desde economia até internacional compõem o que se chama aqui de "temas sociais", que não tratam de política em específico, mas que são temas de relevância pública ${ }^{12}$. Na categoria "temas de entretenimento" são agrupadas as subcategorias de "variedades/cultura" e "esportes". Destaca-se que toda essa categorização é feita considerando-se 0 tema da postagem e não a linguagem ou a forma

0 livro de códigos consiste num arquivo desenvolvido pelos(as) autores(as) onde constam todas as variáveis a serem coletadas. 0 livro referente a esta pesquisa possui 10 variáveis: 1) portal; 2) título; 3) formato; 4) tamanho do texto; 5) valores-notícia; 6) tema; 7) abrangência do tema; 8) editoria; 9) enquadramento; 10) número de comentários. No caso deste trabalho, apenas a variável tema será analisada.

10 Originalmente, o livro de códigos prevê 15 temáticas possíveis: 1) campanha eleitoral ou partidos políticos, que trata especificamente sobre a disputa; 2) político institucional, que envolve decisões do legislativo, executivo e judiciário; 3) economia; 4) saúde; 5) educação; 6) atendimento a carentes e minorias; 7) infra-estrutura urbana; 8) meio-ambiente; 9) violência e segurança; 10) ético-moral; 11) acidentes; 12) internacional; 13) variedades/cultura; 14) esportes; 15) outros. A partir delas foi possível reagrupar as categorias e criar novas variáveis.

11 A partir da reconfiguração da variável tema, as notícias classificadas como "outros" foram excluídas da análise. Assim, resultou-se num banco com 2.415 entradas -1.170 pertencentes ao G1 e 1.245 do UOL.

12 Tanto os temas políticos quanto sociais são considerados como de interesse público, pois considera-se ambos como hard news. No entanto, é feita divisão entre ambos na última parte deste artigo para compreender o interesse específico da audiência por temas políticos. 
da narrativa utilizada, o que se trata de uma opção dos pesquisadores, seguindo uma parte significativa da literatura citada.

A seguir são apresentados os resultados a partir dessas três subdivisões e a distribuição durante os anos analisados ${ }^{13}$. Utiliza-se 0 teste de quiquadrado para testar a relação de variação entre as variáveis - tema e ano - e os resíduos padronizados para identificar as categorias que mais se aproximam ou se distanciam dentro desta relação. A sistematização dos dados foi feita utilizando-se do Excel para a codificação e 0 SPSS para a elaboração dos testes e gráficos.

\section{Apresentação e discussão dos resultados}

A primeira análise diz respeito à quantidade de notícias hard e soft buscada em cada portal de notícia. Os dados dos anos de 2012, 2013 e 2014 foram agrupados neste momento para proporcionar uma visão geral do interesse do leitor no período todo ${ }^{14}$. Os dados indicam que no total dos três anos, os leitores preferiram buscar mais notícias de cunho hard no G1 e (77,9\%) e procuraram por temas soft no portal UOL $(64,3 \%)$.

Tabela 1: Percentual de temas hard $\mathrm{x}$ soft em cada portal ${ }^{15}$

\begin{tabular}{c|c|c|c}
\hline \multicolumn{2}{c}{ Portal } & \multicolumn{1}{c}{ Frequência } & $\%$ \\
\hline \multirow{4}{*}{ G1 } & Hard News & 912 & $\mathbf{7 7 , 9}$ \\
\cline { 2 - 4 } & Soft News & 258 & 22,1 \\
\cline { 2 - 4 } & Total & 1170 & 100 \\
\hline \multirow{3}{*}{ UOL } & Hard News & 444 & 35,7 \\
\cline { 2 - 4 } & Soft News & 801 & $\mathbf{6 4 , 3}$ \\
\cline { 2 - 4 } & Total & 1245 & 100 \\
\hline
\end{tabular}

Fonte: Elaboração própria (2016)

13 Ressalta-se que não se trata de um estudo longitudinal para explicar diferenças ao longo do tempo. 0 objetivo é perceber diferenças a partir a comparação entre três anos: um com eleições locais, outro não eleitoral e outro com disputa nacional.

14 Quando aborda-se a mudança no perfil de acesso aos portais nos anos pesquisados, não se está referindo aos mesmos leitores que tiveram seu interesse alterado. 0 que há é uma alteração no perfil de acesso que pode ou não ser feito pelas mesmas pessoas, mas isso é algo que não há como saber.

15 As notícias que não se enquadravam nas duas categorias foram excluídas da análise. Para conhecimento, foram 64 casos ausentes na Folha; 174 no G1; e 75 no portal UOL. 
As diferenças encontradas aqui evidenciam a natureza de cada veículo ${ }^{16}$ : embora ambos sejam ligados a grupos da mídia hegemônica, o G1 - que se coloca como portal exclusivo de notícias informativas - é o mais acessado para 0 consumo de notícias hard. Por ser o canal oficial do jornalismo da Rede Globo na rede, o portal herda a imagem e legitimidade que o público tem para com o canal televisivo, acreditando que o conteúdo publicado ali tem confiabilidade. 0 UOL, por outro lado, por ser considerado um portal abrangente (BARBOSA, 2002) com diferentes tipos de conteúdo, é mais acessado para 0 consumo de notícias soft.

Verifica-se que há uma segmentação da audiência entre os portais: 0 G1, focado no conteúdo informativo regionalizado, é acessado com uma finalidade; já o UOL, veículo que congrega diferentes tipos de conteúdo, informativos e de entretenimento, além de ser majoritariamente nacional, possui leitores que estão interessados no consumo de notícias mais leves. Dialogando com o conceito de tabloidização indicada por Chagas (2016), observa-se, no caso do UOL, que os temas de interesse privado - que não oferecem informação substancial ao debate público acabam ocupando espaço de temas de maior relevância, o que demonstra essa tendência de forma mais evidente. É como se de cada 10 matérias mais acessadas, 6 delas fossem sobre entretenimento, destacando a centralidade do infotenimento (AGUIAR; BARSOTTI, 2016).

Essa mesma tendência não é verificada de forma tão evidente no G1, no qual se percebe que pouco mais de $20 \%$ das notícias mais lidas são sobre entretenimento. Não chega a ser próximo do UOL, que tem três vezes mais procura por entretenimento, mas pode-se dizer que dá indícios de que mesmo em locais onde o foco não é 0 entretenimento - como é 0 caso do G1 -, 0 leitor busca aquilo que lhe interessa, mesmo que essas notícias não estejam nas áreas de maior destaque da página (MASSUCHIN; TAVARES, 2016). Para ilustrar as diferenças, apresenta-se o gráfico a seguir. 


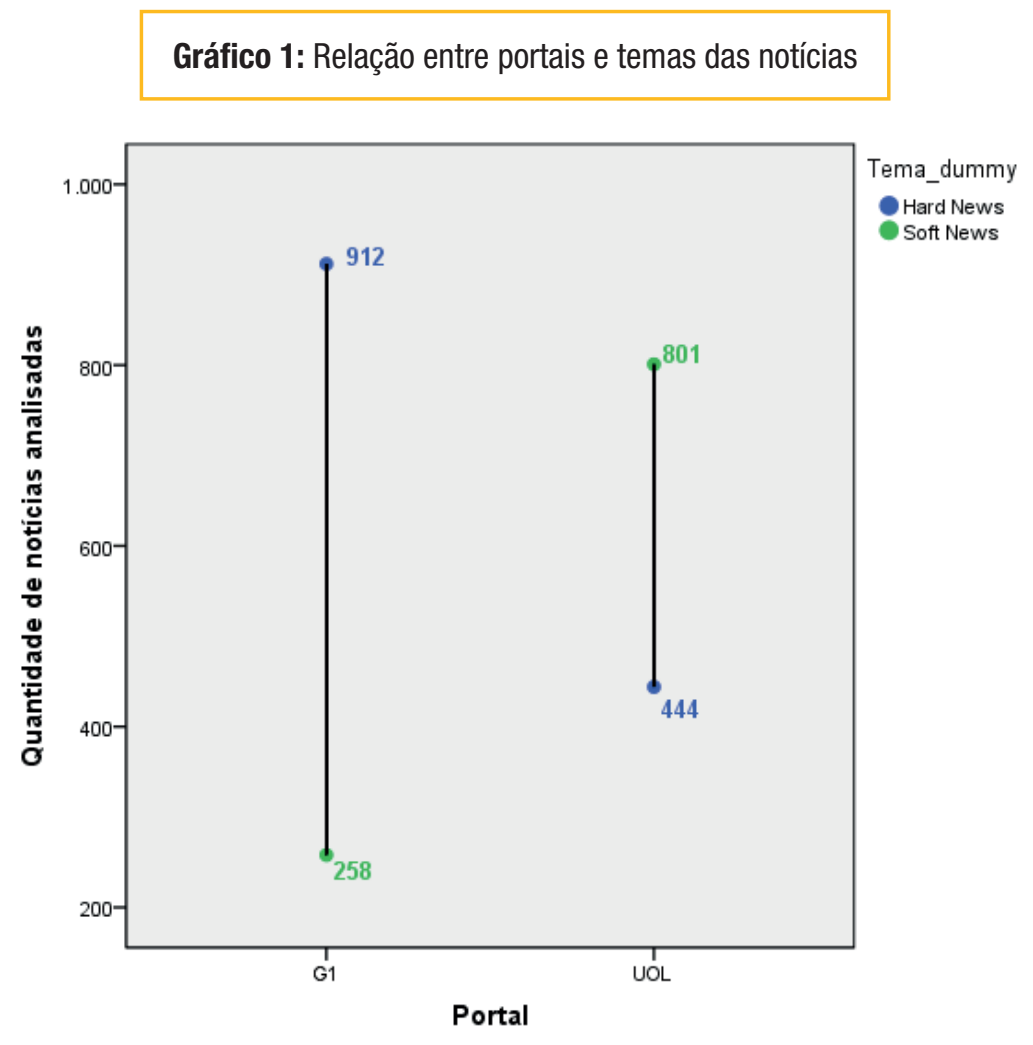

Fonte: Elaboração própria (2016)

Embora não se possa fazer nenhuma afirmação sobre o quanto estes dados influenciam na produção, já que a pesquisa não entrevista os produtores e não acompanha a rotina desses portais, é possível dialogar com Shoemaker e Vos (2011) e Barsotti (2014) que levantam a importância do público na escolha das notícias. Ao ler mais notícias sobre entretenimento, os produtores perceberão que estes são os assuntos que mais chamam a atenção e, assim, modificam ou intensificam tal produção, resultando na tabloidização em função da questão financeira dos veículos. Portanto, o consumo maior de notícias soft pode interferir no processo produtivo, servindo como um gate que pode orientar o portal na produção de notícias mais ou menos informativas, de acordo com o interesse do leitor.
Com 0 gráfico é possível perceber a amplitude entre os temas hard e soft em cada portal. 0 que mais apresenta diferença é 0 G1, onde se tem 258 notícias consideradas soft ao longo dos três anos, e 912 classificadas como hard. Já para o UOL a posição se inverte. No eixo inferior estão as notícias de cunho hard, que totalizaram 444 , ao passo que a grande procura foi por temas soft, tendo um total de 801 matérias identificadas no período. Esses dados proporcionam uma visão geral dos portais, mas que não permitem, ainda, ver diferenças entre os períodos, que é o objetivo principal deste artigo. Para identificar se há mudanças entre os períodos apresenta-se a tabela 2 , agora dividida conforme os anos. 
Tabela 2: Segmentação dos portais quanto ao tipo de conteúdo e os anos analisados

\begin{tabular}{|c|c|c|c|c|c|c|}
\hline & Portal & & 2012 & 2013 & 2014 & Total \\
\hline \multirow{8}{*}{$\mathrm{G} 1$} & \multirow{3}{*}{ Hard News } & Freq. & 257 & 314 & 341 & 912 \\
\hline & & $\%$ & $68,20 \%$ & $80,10 \%$ & $85 \%$ & $77,90 \%$ \\
\hline & & Res. & $-2,2$ & 0,5 & 1,6 & \\
\hline & \multirow{3}{*}{ Soft News } & Freq. & 120 & 78 & 60 & 258 \\
\hline & & $\%$ & $31,80 \%$ & $19,90 \%$ & $15 \%$ & $22,10 \%$ \\
\hline & & Res. & 4 & $-0,9$ & -3 & \\
\hline & \multirow{2}{*}{ Total } & Freq. & 377 & 392 & 401 & 1170 \\
\hline & & $\%$ & $100 \%$ & $100 \%$ & $100 \%$ & $100 \%$ \\
\hline \multirow{8}{*}{ UOL } & \multirow{3}{*}{ Hard News } & Freq. & 115 & 161 & 168 & 444 \\
\hline & & $\%$ & $26,90 \%$ & $38,40 \%$ & $42,10 \%$ & $35,70 \%$ \\
\hline & & Res. & -3 & 0,9 & 2,2 & \\
\hline & \multirow{3}{*}{ Soft News } & Freq. & 312 & 258 & 231 & 801 \\
\hline & & $\%$ & $73,10 \%$ & $61,60 \%$ & $57,90 \%$ & $64,30 \%$ \\
\hline & & Res. & 2,2 & $-0,7$ & $-1,6$ & \\
\hline & \multirow{2}{*}{ Total } & Freq. & 427 & 419 & 399 & 1245 \\
\hline & & $\%$ & $100 \%$ & $100 \%$ & $100 \%$ & $100 \%$ \\
\hline
\end{tabular}

G1: Chi-Square: 33,754 (sig 0,000)

UOL: Chi-Square: 22,797 (sig 0,000)

Fonte: Elaboração própria (2016)

A tabela acima possibilita identificar que 0

interesse dos leitores dos portais apresentou

mudanças entre os períodos, ainda que

os perfis anteriormente identificados se

mantenham para cada um dos portais durante

os três anos. 0 teste Chi-Square ${ }^{17}$ mostra

qual portal apresentou a relação mais forte

na mudança da distribuição, sendo que 0

maior valor foi obtido pelo G1 $(33,754)$, que

apresenta maior mudança.
Para complementar, os resíduos padronizados indicam a força da relação entre as categorias das variáveis "temas" e "ano", válido apenas para os casos onde o valor é maior ou menor que $| \pm 1,96|^{18}$. Nota-se, por exemplo, que os resíduos positivos significativos para a categoria soft dos dois veículos se concentram em 2012 (4,0 e $2,2)$. Dos três anos, a maior parte das notícias de entretenimento foi mais procurada em 2012, em relação aos outros períodos, o que reafirma

0 Chi-Square consiste num teste de hipóteses que constata a relação entre duas variáveis categóricas.

18 0s resíduos padronizados indicam em quais categorias estão as relações mais fortes, seja de aproximação (quando 0 resíduo é positivo) ou de distanciamento (quando é negativo). 
a tendência da diminuição da procura por temas soft e aumento da procura por temas hard.

Isso fica bastante evidente no G1, onde se percebe uma diferença clara entre notícias soft. 0s resíduos indicam que há uma forte relação entre $s o f t$ e 0 ano de 2012 para 0 portal $(4,0)$, embora isso mude nos anos seguintes. Em 2014, 0 resultado encontrado é bastante diferente $(-3,0)$, o que significa dizer que naquele ano 0 portal teve tendência em ser menos procurado pelos leitores para se informarem sobre notícias mais leves em relação a 2012 e 2013. No G1, se em 2012 os temas hard representavam $62 \%$ das mais lidas, em 2014 passou para 85\%, com um aumento de 23 pontos percentuais. Ainda que notícias de entretenimento tendam a ser bastante procuradas pelo público, conforme identificou Vidal (2009) e Lee (2012), os resultados indicam que as notícias soft têm perdido um pouco do interesse do público, pelo menos no período analisado, o que pode ser explicado pelo contexto eleitoral.

No UOL, apesar do seu caráter de entretenimento, há que se destacar 0 aumento da ênfase nas notícias hard. Em 2012, o portal tinha relação mais fraca com essa temática $(-3,0)$, enquanto que em 2014 verifica-se uma mudança na orientação do público, que passou a procurar mais por notícias dessa natureza $(2,2)$. Essa mudança não é ingênua; a crise política que começou em 2013 com as manifestações de junho, junto com o cenário eleitoral podem, ter influenciado na necessidade de buscar por informação desse tipo, mesmo em portais que são conhecidos pelas características mais soft, como é o caso do UOL.

Ainda para ilustrar essas mudanças, apresentam-se os próximos gráficos, que indicam a relação de cada portal com os temas ao longo dos três anos, a partir da distribuição entre hardnews e softnews. No caso do G1, 0 gráfico reafirma os dados trazidos pela última tabela de que há uma tendência de queda na busca por informações soft ao mesmo tempo em que cresce 0 interesse por notícias hard. Como se pode observar, no primeiro ano pesquisado a diferença entre os tipos de temas é bem menor do que a identificada nos anos seguintes, lembrando que aqui o predomínio também sempre foi das notícias hard. Comparado a 2012, o número das matérias soft acessado pelos leitores caiu pela metade, de 120 para 60 . 


\section{Gráfico 2: Distribuição de temas por ano no G1 e UOL}
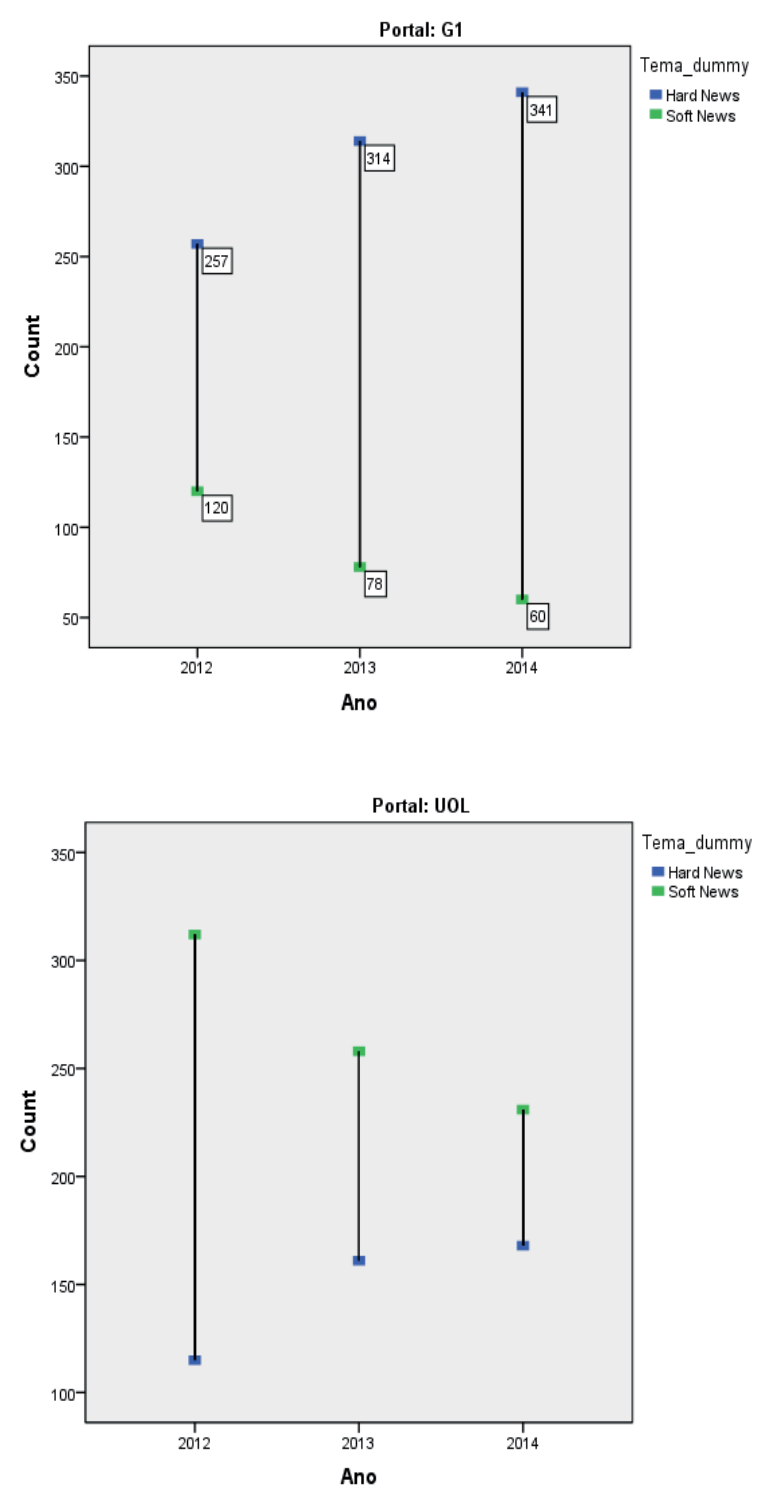

Fonte: Elaboração própria (2016)

Se no G1 há uma tendência de aumento da diferença entre a procura por temas hard e soft, no caso do UOL a orientação é em diminuir. Vale ressaltar que aqui o destaque geral é para as softnews. Essa inversão ocorre porque o portal foi bastante procurado para consumo de notícias soft em 2012, mas com uma disposição em mudar esse cenário nos anos seguintes. Em 2013 constata-se grande diferença em relação aos dados do ano anterior, orientação que segue em 2014. 0 número de notícias acessadas de temática soft caiu de 312 para 231, enquanto que notícias hard passaram a aparecer de maneira mais frequente entre as mais lidas, saltando de 115 para 168. Assim, se 0 cenário de 2013 e 2014 levou a essa busca por notícias 
de interesse público, isso também pode ser estendido ao UOL.

0 UOL, como se verifica, mantém a predominância por entretenimento nos três períodos, mas diminuindo essa tendência e ampliando a busca por temas de interesse público. Enquanto alguns trabalhos mostram a apropriação do entretenimento pela internet (LIMA, 2009; BERROCAL; CAMPOS; REDONDO, 2012; LEE, 2012), o público desses portais estudados tem demonstrado um retorno ao papel do jornalismo enquanto fonte de informação de interesse público tendo espaço na internet, a partir da definição de Tuchman (1983).

Como já foi indicado anteriormente de modo sintético, alguns acontecimentos podem explicar as diferenças encontradas até então. Em 2012, apesar de ser um ano eleitoral, não houve centralidade suficiente para 0 tema tomar frente das notícias de interesse público e gerar maior interesse do que as notícias soft. Isso se deve ao fato de se tratar de uma disputa local e os portais terem uma proposta editorial regional/nacional. 0 ano de 2013 foi marcado por protestos e grande insatisfação popular relacionada ao transporte, saúde e corrupção, impulsionados principalmente pelos investimentos realizados para a Copa do Mundo que aconteceria no ano seguinte e pelo início das prisões dos políticos condenados pelo Mensalão.

Outra possível explicação para o contínuo aumento do interesse por esse tipo de conteúdo refere-se ao início das investigações da Operação Lava Jato (que se deu em março de 2014) e 0 período eleitoral daquele ano, onde os eleitores brasileiros foram às urnas escolher presidente, governadores, deputados estaduais e federais, e senadores. Essas vertentes explicativas podem ter gerado esse aumento de interesse por temáticas hard, ao mesmo tempo em que houve queda na busca por temas soft. Percebese uma inclinação para a busca de notícias de interesse público, em oposição à tendência de tabloidização (CHAGAS, 2016).

A fim de detalhar esses resultados e dar atenção mais específica à temática política, os temas são divididos, a seguir, entre político, interesse social e entretenimento. 0 objetivo é identificar onde se concentra 0 interesse por política e se existe alguma relação com os períodos eleitorais, ainda que os dados anteriores tenham indicado pouca importância da disputa local e uma possível centralidade na de 2014.

Em nenhum dos dois portais houve, aparentemente, grande preocupação em buscar por temas políticos no período pesquisado, já que o maior percentual encontrado no G1 foi em 2014, com 11,7\%; e no UOL, com 12,5\%. Os temas de interesse social, por outro lado, estiveram mais presentes entre as mais lidas no G1, apesar de haver variação no período nos dois portais. Já os temas de entretenimento continuam predominando no UOL, embora apresentem quedas no período de modo generalizado. 
Tabela 3: Temas específicos entre os anos analisados

\begin{tabular}{|c|c|c|c|c|c|c|}
\hline & Portais & & 2012 & 2013 & 2014 & Total \\
\hline \multirow{11}{*}{ G1 } & \multirow{3}{*}{ Temas Políticos } & Freq. & 22 & 6 & 47 & 75 \\
\hline & & $\%$ & $5,80 \%$ & $1,50 \%$ & $11,70 \%$ & $6,40 \%$ \\
\hline & & Resíduo & $-0,4$ & $-3,8$ & 4,2 & \\
\hline & \multirow{3}{*}{ Temas sociais } & Freq. & 235 & 308 & 294 & 837 \\
\hline & & $\%$ & $62,30 \%$ & $78,60 \%$ & $73,30 \%$ & $71,50 \%$ \\
\hline & & Resíduo & $-2,1$ & 1,6 & 0,4 & \\
\hline & \multirow{3}{*}{ Temas de Entretenimento } & Freq. & 120 & 78 & 60 & 258 \\
\hline & & $\%$ & $31,80 \%$ & $19,90 \%$ & $15 \%$ & $22,10 \%$ \\
\hline & & Resíduo & 4 & $-0,9$ & -3 & \\
\hline & \multirow{2}{*}{ Total } & Freq. & 377 & 392 & 401 & 1170 \\
\hline & & $\%$ & $100 \%$ & $100 \%$ & $100 \%$ & $100 \%$ \\
\hline \multirow{11}{*}{ UOL } & \multirow{3}{*}{ Temas Políticos } & Freq. & 20 & 16 & 50 & 86 \\
\hline & & $\%$ & $4,70 \%$ & $3,80 \%$ & $12,50 \%$ & $6,90 \%$ \\
\hline & & Resíduo & $-1,7$ & $-2,4$ & 4,3 & \\
\hline & \multirow{3}{*}{ Temas sociais } & Freq. & 95 & 145 & 118 & 358 \\
\hline & & $\%$ & $22,20 \%$ & $34,60 \%$ & $29,60 \%$ & $28,80 \%$ \\
\hline & & Resíduo & $-2,5$ & 2,2 & 0,3 & \\
\hline & \multirow{3}{*}{ Temas de Entretenimento } & Freq. & 312 & 258 & 231 & 801 \\
\hline & & $\%$ & $73,10 \%$ & $61,60 \%$ & $57,90 \%$ & $64,30 \%$ \\
\hline & & Resíduo & 2,2 & $-0,7$ & $-1,6$ & \\
\hline & \multirow{2}{*}{ Total } & Freq. & 427 & 419 & 399 & 1245 \\
\hline & & $\%$ & $100 \%$ & $100 \%$ & $100 \%$ & $100 \%$ \\
\hline
\end{tabular}

G1: Chi-Square: 66,060 (sig 0,000)

UOL: Chi-Square: 46,611 (sig 0,000)

Fonte: Elaboração própria (2016)

Para testar se essas diferenças identificadas ao longo dos três anos são significativas, apresentase 0 resultado do teste qui-quadrado e os resíduos padronizados. 0 portal G1 apresenta duas relações de destaque: os temas de entretenimento que possuíam alta concentração no ano de $2012(4,0)$ tiveram acentuada queda em 2014, conforme indica 0 resíduo negativo de -3,0. 0 outro destaque se dá para os temas políticos, que possuem forte relação com 0 ano de 2014 (4,2), reiterando a centralidade das eleições. Isso significa dizer que houve uma mudança no perfil do acesso ao portal nestes períodos, pois se percebeu a diminuição do consumo de notícias de entretenimento e maior atenção para matérias caracterizadas por temas políticos, pelo menos no último ano eleitoral.

0 UOL também apresenta mudanças significativas entre suas distribuições, ainda que tenha concentração em entretenimento quando 
comparado ao outro portal. Os temas de entretenimento apresentam relação positiva com 0 ano de 2012; em 2013 o destaque são os temas de interesse social $(2,2) ;$ e 2014 foi marcado pela alta concentração de temas políticos entre os principais interesses dos leitores $(4,3)$. 0 s resultados indicam, sobretudo, que há uma tendência de mudança no interesse da audiência que acessa esses portais, fazendo com que a internet tenha um papel mais relevante no que diz respeito a munir os leitores com informações para o debate público e isso fica perceptível, principalmente, com o ano eleitoral de 2014. Desenvolve-se melhor esse argumento a seguir, nas conclusões.

\section{Conclusões}

0 objetivo principal deste artigo foi investigar as temáticas das notícias "mais lidas do dia" de dois portais informativos, a fim de verificar padrões e mudanças no interesse do leitor. Para isso, foram analisados os conteúdos do G1 e UOL, comparando os anos de 2012, 2013 e 2014, a partir do material coletado no ranking diário das notícias mais lidas. A hipótese inicial confirmouse, pois se identifica a segmentação, mas também uma alteração nos interesses dos leitores entre os três períodos distintos.

Fica evidente que, de fato, os portais têm uma segmentação: 0 G1 é 0 veículo mais procurado para o consumo de notícias com temas de interesse público, especialmente de temas sociais. 0 UOL, por outro lado, ainda é lembrado no momento de procurar por notícias de entretenimento. Isso mostra que há diferentes padrões pela busca de informação na rede, 0 que diferencia os portais enquanto fonte de informação e, principalmente, na sua função dentro do debate público.

Outro achado relevante desta análise diz respeito a uma tendência geral de queda na busca por notícias mais leves nos dois portais, indicando alterações temporais conforme os contextos de cada ano analisado. As notícias soft estão dando lugar para notícias hard - pelo menos no acompanhamento feito nos três anos, nesses portais. Isso demonstra uma mudança no perfil de acessos, o que pode ser motivado por fatores inerentes à realidade social, como foi abordado ao longo da análise. Ainda que 0 entretenimento esteja tão presente na rede quanto os conteúdos informativos, o leitor dos portais tem estado mais disposto a buscar informação de interesse público. Esse achado coloca em perspectiva as conclusões de Lee (2012) que observou que as notícias mais lidas dos sites do New York Times e do The Washington Post eram voltadas ao entretenimento; e de Vidal (2009), que identificou que o público leitor dos sites d'0 Globo e Folha procurava mais por notícias de interesse do público ao invés daquelas de interesse público.

Por fim, quando olhamos para as temáticas específicas e 0 lugar do tema político no interesse dos leitores, também se observa diferenças entre 
os veículos e períodos. 0 tema ganhou maior atenção dos leitores em 2014, o que leva a afirmar, ainda que com cautela, que o maior consumo de notícias com essa temática proporciona argumentos substanciais para o debate público e torna os portais uma fonte importante de notícias em períodos eleitorais, já que ele tende a ser procurado até mesmo por quem, em outros momentos, não o utiliza para tal finalidade.

Ainda que se conclua que as notícias hard aparecem com tendência crescente no interesse dos leitores, há bastante conteúdo soft entre as buscas do público, o que corrobora com o que Lima (2009) e Berrocal, Campos e Redondo (2012) falam quando mencionam que a rede é um lugar onde esse tipo de conteúdo tem se disseminado. 0s números são altos e vale ressaltálos, já que a discussão sobre infotenimento e tabloidização tem se destacado na literatura mais recente (LEE, 2012; AGUIAR; BARSOTTI, 2016; CHAGAS, 2016). Essa popularização das notícias de entretenimento pode interferir no processo de produção da notícia, conforme já falavam Shoemaker et al. (2010) e Barsotti (2014), além de demonstrar a pressão que os veículos tradicionais que migram para a web sofrem das notícias mais populares (ESSER, 1999; LIMA, 2009).

Os dados comparativos, por outro lado, indicam que 0 consumo de notícias de maior relevância vem se tornando uma realidade entre os principais portais informativos brasileiros. Se isso é resultado de conjunturas específicas ou é um padrão que tende a se manter, apenas 0 acompanhamento sistemático da produção nos próximos anos poderá comprovar. Porém, os dados dos três anos indicam uma retomada dos temas de interesse público (social e político), o que é positivo para a circulação de informação em período eleitoral e, também, para o debate público, mesmo em outros períodos não-eleitorais. Mesmo que a televisão ainda seja o meio mais usado para buscar informações, segundo a Pesquisa Brasileira de Mídia 2016, a internet pouco a pouco passa a ser uma fonte de informação reconhecida e utilizada.

Dessa forma, acredita-se que este artigo pode auxiliar no preenchimento de algumas lacunas. A primeira é oferecendo um perfil do consumo de notícias nos portais e indicando o interesse dos leitores por distintos tipos de conteúdo. São poucos, ainda, os esforços sistematizados para identificar o consumo de informação jornalística. Além disso, é relevante conhecer o perfil dos conteúdos mais buscados, relacionando estes resultados com os contextos eleitorais, inclusive observando as mudanças que as disputas trazem no consumo de notícias. Reitera-se que a pesquisa é um esforço comparativo que oferece subsídios para pesquisas futuras, pois indica, entre outros resultados, as diferenças entre portais, o que não se altera de modo constante, a não ser que haja alguma mudança editorial. Por fim, pesquisas comparativas e longitudinais podem ser feitas para períodos eleitorais futuros, utilizandose das perspectivas teórica e metodológica sistematizadas no artigo. 


\section{Referências Bibliográficas}

AGUIAR, Leonel.; BARSOTTI, Adriana. 0 jornalismo sensorial e 0 infotenimento na produção de notícias.

Revista Pauta Geral - Estudos em Jornalismo, Ponta Grossa, v.3, n.1, p. 57-75, 2016.

BARBOSA, Suzana. Jornalismo online: dos sites noticiosos aos portais locais. BOCC - Biblioteca Online de Ciências da Comunicação, p. 1-17, 2002. Disponível em: < http://bocc.unisinos.br/pag/barbosa-suzanajornalismo-online.pdf $>$. Acesso em: 12 de dezembro de 2016.

BARSOTTI, Adriana. Transformações contemporâneas nas práticas jornalísticas: o jornalista online como mobilizador de audiência. E-Compós, Brasília, v. 17, n. 1, p. 1-20, 2014.

BAYM, Geoffrey. Infotainment. The International Encyclopedia of Communication. Donsbach, Wolfgang: Blackwell Publishing, 2008.

BERROCAL, Salomé; DOMÍNGUEZ, Eva; GARCÍA, Marta. El "infoentretenimiento" político en Internet: La presencia de cinco líderes europeos en YouTube. RIPS, Santiago de Compostela, v. 11, n. 4, 107-131, 2012.

BLANCO, Víctor. Opinión pública y democracia deliberativa: médios, sondeos y urnas. Madrid: ISTMO, 2000 .

CHAGAS, Victor. Economia política do jornalismo popular em perspectiva comparada: uma análise sobre a tabloidização no Brasil, na Índia e na África do Sul. Brazilian Journalism Research, Brasília, v. 12, n. 1, p. $60-81,2016$.

CERVI, Emerson Urizzi. Métodos quantitativos nas ciências sociais: uma abordagem alternativa ao fetichismo dos números e ao debate com qualitativistas. In: BOURGUIGNON, Jussara. Pesquisa Social: reflexões teóricas e metodológicas. Ponta Grossa: TODAPALAVRA, 2009. p.125-143. .; MASSUCHIN, Michele Goulart. 0 que interessa ao público nos portais informativos? Revista Compolítica, v. 2, n. 3, p. 123-154, 2013.

ESSER, Frank. 'Tabloidization' of the news: a comparative analysis of Anglo-American and German press journalism. European Journal of Communication, v. 14, n. 3, p. 291-324, 1999.

GOMES, Itania Maria Mota. 0 Infotainment e a Cultura Televisiva. In: FREIRE FILHO, João. (Org.). A TV em transição. Tendências de programação no Brasil e no mundo. 1 ed. Porto Alegre: Sulina, 2009.

HABERMAS, Jurgen. Political communication in media society: Does democracy still enjoy an epistemic dimension? the impact of normative theory on empirical research. Communication theory, Austin, v. 16, n. 4, 411-426, 2006.

KRIPPENDORFF, Klaus. Metodologia de anáisis de contenido: teoría y práctica. Barcelona: Paidós, 1990.

LEE, Shing Haeng. The end of tradicional gatekeeper. Gnovis, Washington, v. X, n. I, 2012. Disponível em: $<$ http://www.gnovisjournal.org/2012/04/26/the-end-ofthe-traditional-gatekeeper/\#comment-425>. Acesso em: 10 de dezembro de 2016.

LIMA, Aanastasia. Is there a tabloidization of online news? A content analysis of traditional news websites. Gnovis, Washington v. X, n. I, 2009. Disponível em: <http://www.gnovisjournal.org/2009/12/22/theretabloidization-online-news-content-analysis-traditionalnews-websites/> . Acesso em: 10 de dezembro de 2016.

MASSUCHIN, Michele Goulart; TAVARES, Camilla Quesada. Interesse dos leitores e produtores em perspectiva comparada: uma análise da produção jornalística e das notícias mais lidas durante 0 período eleitoral de 2014. In: CERVI, Emerson Urizzi; MASSUCHIN, Michele Goulart; CARVALHO, Fernanda Cavassana de (Orgs). Internet e eleições no Brasil. Curitiba: CPOP, 2016.

McCOMBS, Maxwell. A Teoria da agenda: a mídia e a opinião pública. Petrópolis: Vozes, 2009. 
MUNDIM, Pedro Santos. As consequências políticas do jornalismo de entretenimento. Líbero, São Paulo, v.13, n. 25, p. 131-142, 2010.

NÓRA, Gabriela. Jornalismo impresso na era digital: uma crítica à segmentação do público e à fragmentação do noticiário. Rumores, São Paulo, ed. 10, ano 5, p. 297-314, 2011.

PRIOR, Markus. Any Good News in Soft News? The Impact of Soft News Preference on Political Knowledge. Political Communication, Philadelphia, p. 149-171, 2010.

SHOEMAKER, Pamela; VOS, Timothy. Teoria do

Gatekeeping. Seleção e construção da notícia. Porto Alegre: Penso, 2011. . et al. 0s leitores como Gatekeepers das notícias on-line: Brasil, China e Estados Unidos. Sociedade Brasileira de Pesquisa em Jornalismo, Brasília, v. 6, n. 1, p. 58-83, 2010.

TUCHMAN, Gaye. La produción de la noticia. Estudio sobre la construcción de la realidad. Barcelona: Editorial Gustavo Gilli, 1983.

VIDAL, Delcia Maria de Mattos. Imprensa, Jornalismo e Interesse Público. Tese de Doutoramento, Universidade de Brasília, Brasília, Brasil, 2009. Disponível em: < http://bdtd.bce. unb.br/tedesimplificado/tde_busca/arquivo. php?codArquivo $=6051>$. Acesso em: 12 de dezembro de 2016.

WOLF, Mauro. Teorias da Comunicação de Massa. São Paulo: WMF Martins Fontes, 2010.

ZALLER, John. A New Standard of News Quality: Burglar Alarms for the Monitorial Citizen. Political Communication, Philadelphia, 20, p. 109-130, 2003. 


\section{Public interest or entertainment: what kind of information the public searches on the internet?}

\section{Abstract}

The article presents research results on reader's preferences of two Brazilian information portals - G1 and UOL - made up from the most accessed articles. The objective is to verify if there is a segmentation trend among the portals, proposing a comparative analysis through 2012, 2013 and 2014. Altogether, 2,637 news items belonging to the "most read" sections of the day were collected. The methodology used is quantitative content analysis and the results indicate that there is segmentation between the portals - while G1 is most sought for news concerning public interest, UOL is accessed for entertainment. On the other hand, despite the fact that segmentation persists over the years surveyed, the interest in news that involves political and social issues has grown.

\section{Keywords}

Informative websites. Public interest. Entertainment

\section{Interés público o entretenimiento: qué tipo de información el lector busca en Internet?}

\section{Resumen}

El artículo presenta resultados de una investigación sobre las preferencias de los lectores de dos portales informativos brasileños - G1 y UOL - hecha a partir de las noticias más visualizadas. El objetivo es verificar si hay tendencia de segmentación entre los portales, proponiendo un análisis comparativo de los años 2012, 2013 y 2014. En total, fueron analizadas 2.637 noticias pertenecientes a las secciones "más leídas del día". La metodología utilizada es cuantitativa de análisis de contenido y los resultados indican que hay segmentación entre los portales - mientras que el G1 es más buscado para el consumo de noticias de interés público, el UOL recibe más accesos a los contenidos de entretenimiento. Por otro lado, a pesar de que la segmentación se mantiene en los tres años investigados, el interés por noticias que involucran cuestiones políticas creció entre 2012 y 2014.

\section{Palabras clave}

Portales de noticias. Interés público. Entretenimiento. 


\section{Expediente}

A revista E-Compós é a publicação científica em formato eletrônico da Associação Nacional dos Programas de Pós-Graduação em Comunicação (Compós). Lançada em 2004, tem como principal finalidade difundir a produção acadêmica de pesquisadores da área de Comunicação, inseridos em instituições do Brasil e do exterior.

\section{E-COMPÓS I www.e-compos.org.br I E-ISSN 1808-2599}

Revista da Associação Nacional dos Programas de Pós-Graduação em Comunicação. Brasília, v.20, n.3, set./dez. 2017. A identificação das edições, a partir de 2008 , passa a ser volume anual com três números. Indexada por Latindex I www.latindex.unam.mx

\section{CONSELHO EDITORIAL}

Ada Cristina Machado Silveira, Universidade Federal de Santa Maria, Brasil Alda Cristina Silva da Costa, Universidade Federal do Pará, Brasil Alfredo Luiz Paes de Oliveira Suppia, Universidade Estadual de Campinas, Brasil Ana Regina Barros Rego Leal, Universidade Federal do Piauí, Brasil Ana Carolina Rocha Pessôa Temer, Universidade Federal de Goiás, Brasil André Luiz Martins Lemos, Universidade Federal da Bahia, Brasil Angela Cristina Salgueiro Marques, Universidade Federal de Minas Gerais, Brasil Ângela Freire Prysthon, Universidade Federal de Pernambuco, Brasil Antonio Carlos Hohlfeldt, Pontifícia Universidade Católica do Rio Grande do Sul, Brasil Arthur Ituassu, Pontifícia Universidade Católica do Rio de Janeiro, Brasil

Bruno Campanella, Universidade Federal Fluminense, Brasil

Cláudio Novaes Pinto Coelho, Faculdade Cásper Líbero, Brasil Cárlida Emerim, Universidade Federal de Santa Catarina, Brasil Carlos Eduardo Franciscato, Universidade Federal de Sergipe, Brasil Danilo Rothberg, Universidade Estadual Paulista, Brasil Denise Tavares da Silva, Universidade Federal Fluminense, Brasil Diógenes Lycarião, Universidade Federal do Ceará, Brasil Eduardo Vicente, Universidade de São Paulo, Brasil Eliza Bachega Casadei, Escola Superior de Propaganda e Marketing - SP, Brasil Eneus Trindade, Universidade de São Paulo, Brasil

Erick Felinto de Oliveira, Universidade do Estado do Rio de Janeiro, Brasil Erly Vieira Júnior, Universidade Federal do Espírito Santo, Brasil Francisco de Assis, FIAM-FAAM Centro Universitário, Brasi

Francisco Elinaldo Teixeira, Universidade Estadual de Campinas, Brasil Francisco Gilson R. Pôrto Jr., Universidade Federal do Tocantins, Brasil Frederico de Mello Brandão Tavares, Universidade Federal de Ouro Preto, Brasil Gabriela Reinaldo, Universidade Federal do Ceará, Brasil Gilson Vieira Monteiro, Universidade Federal do Amazonas, Brasil Gustavo Daudt Fischer, Universidade do Vale do Rio dos Sinos, Brasil Itania Maria Mota Gomes, Universidade Federal da Bahia, Brasil Jiani Adriana Bonin, Universidade do Vale do Rio dos Sinos, Brasil José Afonso da Silva Junior, Universidade Federal de Pernambuco, Brasil José Luiz Aidar Prado, Pontifícia Universidade Católica de São Paulo, Brasi Josette Maria Monzani, Universidade Federal de São Carlos, Brasi Juçara Gorski Brittes, Universidade Federal de Ouro Preto, Brasil
Juliana Freire Gutmann, Universidade Federal da Bahia, Brasil Laura Loguercio Cánepa, Universidade Anhembi Morumbi, Brasil Leonel Azevedo de Aguiar, Pontifícia Universidade Católica do Rio de Janeiro, Brasil Letícia Cantarela Matheus, Universidade do Estado do Rio de Janeiro, Brasil Luciana Coutinho Souza, Universidade de Sorocaba, Brasil Maria Ataide Malcher, Universidade Federal do Pará, Brasil Maria Elisabete Antonioli, Escola Superior de Propaganda e Marketing - SP, Brasil Maria das Graças Pinto Coelho, Universidade Federal do Rio Grande do Norte, Brasil Marialva Carlos Barbosa, Universidade Federal do Rio de Janeiro, Brasil Marcel Vieira Barreto Silva, Universidade Federal da Paraíba, Brasil Marcia Tondato, Escola Superior de Propaganda e Marketing, Brasil Marli Santos, Universidade Metodista de São Paulo, Brasil

Márcio Souza Gonçalves, Universidade do Estado do Rio de Janeiro, Brasil Mauricio Mario Monteiro, Universidade Anhembi Morumbi, Brasil Mayka Castellano, Universidade Federal Fluminense, Brasil

Mozahir Salomão Bruck, Pontifícia Universidade Católica de Minas Gerais, Brasil Nisia Martins Rosario, Universidade Federal do Rio Grande do Sul, Brasil Paolo Demuru, Universidade Paulista, Brasil

Paula Melani Rocha, Universidade Estadual de Ponta Grossa, Brasil Potiguara Mendes Silveira Jr, Universidade Federal de Juiz de Fora, Brasil Priscila Ferreira Perazzo, Universidade Municipal de São Caetano do Sul, Brasil Rafael Cardoso Sampaio, Universidade Federal do Paraná, Brasil Rafael Tassi Teixeira, Universidade Tuiuti do Paraná, Brasil Regiane Lucas Garcês, Universidade Federal de Minas Gerais, Brasil Regiane Regina Ribeiro, Universidade Federal do Paraná, Brasil Renata Pitombo Cidreira, Universidade Federal do Recôncavo da Bahia, Brasil Renato Essenfelder, Escola Superior de Propaganda e Marketing, Brasil Roberto Elísio dos Santos, Universidade Municipal de São Caetano do Sul, Brasil Rodolfo Rorato Londero, Universidade Estadual de Londrina, Brasil Roseli Figaro, Universidade de São Paulo, Brasil

Simone Maria Andrade Pereira de Sá, Universidade Federal Fluminense, Brasil Sofia Cavalcanti Zanforlin, Universidade Católica de Brasília, Brasil Sônia Caldas Pessoa, Universidade Federal de Minas Gerais, Brasil Tatiana Oliveira Siciliano, Pontifícia Universidade Católica do Rio de Janeiro, Brasil Thaïs de Mendonça Jorge, Universidade de Brasília, Brasil

Valquiria Michela John, Universidade Federal do Paraná, Brasil

\section{CONSELHO CIENTÍFICO}

Cristiane Freitas Gutfreind, Pontifícia Universidade Católica do Rio Grande do Sul, Brasil | Eduardo Antônio de Jesus, Universidade Federal de Minhas Gerais, Brasil I Eduardo Morettin, Universidade de São Paulo, Brasil I Irene de Araújo Machado, Universidade de São Paulo, Brasil I Miriam de Souza Rossini, Universidade Federal do Rio Grande do Sul, Brasil

\section{COMISSÃO EDITORIAL}

Eduardo Antonio de Jesus, Universidade Federal de Minas Gerais, Brasil I Igor Pinto Sacramento, Universidade Federal do Rio de Janeiro, Brasil I Kelly Cristina de Souza Prudencio, Universidade Federal do Paraná, Brasil I Osmar Gonçalves dos Reis Filho, Universidade Federal do Ceará, Brasil I Rafael Grohmann, FIAMFAAM - Centro Universitário, Brasil (editor associado)

\section{CONSULTORES AD HOC}

Afonso de Albuquerque, Universidade Federal Fluminense, Brasil I Francisco Rüdiger, Pontifícia Universidade Católica do Rio Grande do Sul, Brasil I Gislene da Silva, Universidade Federal de Santa Cataria, Brasil I Luiz Cláudio Martino Universidade de Brasília, Brasil I Magali Nascimento Cunha, Universidade Metodista de São Paulo, Brasil I Márcia Franz Amaral, Universidade Federal de Santa Maria, Brasil I Tania Marcia Cezar Hoff, Escola Superior de Propaganda e Marketing, Brasil I Raquel Paiva, Universidade Federal do Rio de Janeiro, Brasil

\section{EQUIPE TÉCNICA}

ASSISTENTE EDITORIAL Márcio Zanetti Negrini I REVISÃO DE TEXTOS Melina Santos I EDITORAÇÃO ELETRÔNICA Roka Estúdio
COMPÓS I www.compos.org.br

Associação Nacional dos Programas de Pós-Graduação em Comunicação

Presidente

Marco Roxo

Programa de Pós-Graduação em Comunicação - UFF marcos-roxo@uol.com.br

Vice-Presidente

Isaltina Gomes

Programa de Pós-Graduação em Comunicação - UFPE isaltina@gmail.com

Secretária-Geral

Gisela Castro

Programa de Pós-Graduação em Comunicação

e Práticas de Consumo - ESPM

castro.gisela@gmail.com

CONTATO I revistaecompos@gmail.com 